JURNAL PENDIDIKAN USIA DINI

DOI: https://doi.org/10.21009/JPUD.122
DOI: https://doi.org/10.21009/JPUD.122.14

\title{
PENINGKATAN KEPERCAYAAN DIRI ANAK MELALUI METODE TALKING STICK
}

\author{
Rara Agista Olivantina ${ }^{1}$, Suparno $^{3}$ \\ Universitas Negeri Yogyakarta \\ E-mail: rara.agista@yahoo.com ${ }^{1}$, suparno_plb@uny.ac.id ${ }^{3}$ \\ Opsasi Olivantina ${ }^{2}$ \\ Universitas Negeri Jakarta \\ E-mail: opsasi_olivantina@yahoo.com²
}

\begin{abstract}
ABSTRAK
This study aims to to described the process and lessons through the activities of talking stick method that would improve self confidence in kindergarten $B T K A B A 01$ Malang. The subject of this research totaled 14 children, a method of this research is research the act of referring to a model research the act of class of Kemmis and McTaggart which includes four stage: planning, action, observation, and reflection. This research consisting of 2 cycles, each cycle consists of twelve meeting. Data analysis technique used in this research is quantitative and quantitative data analysis. Qualitative data analysis by analyzing data from observation record, interview record, and a documentation note during the research by steps the reduction of the data, data display, and data verification. Quantitative data analysis with descriptive statistics that compares the results obtained from pre cycle, first cycle, and second cycle. The result of this research show that there is an improve in self confidence of children through the implementation of talking stick method, the average self confidence score of children on the pre cycle is 22, improved in the first cycle to 28 and the second cycle to 41 .
\end{abstract}

Keywords: Early Chilhood, Self confidence, Talking stick method

Penelitian ini bertujuan untuk mendeskripsikan proses dan hasil pembelajaran melalui pelaksanaan metode talking stick yang dapat meningkatkan kepercayaan diri anak kelompok B TK ABA 01 Kabupaten Malang. Subyek penelitian ini berjumlah 14 anak. Metode penelitian yang digunakan mengacu pada model penelitian tindakan Kemmis dan McTaggart yang terdiri dari empat tahap yakni: perencanaan, tindakan, pengamatan dan refleksi. Penelitian ini terdiri dari dua siklus masingmasing siklus terdiri dari dua belas kali pertemuan. Teknik analisis data digunakan dalam penelitian ini adalah analisis data kuantitatif dan kualitatif. Analisis data kualitatif dengan cara menganalisis data dari hasil catatan observasi, catatan wawancara dan catatan dokumentasi selama penelitian dengan langkah-langkah reduksi data, penyajian data dan verifikasi data. Analisis data kuantitatif dengan statistik deskriptif yaitu membandingkan hasil yang diperoleh dari pra tindakan, siklus pertama dan siklus kedua. Hasil penelitian ini menunjukkan adanya peningkatan kepercayaan diri anak melalui pelaksanaan metode talking stick, dapat dibuktikan dengan rata-rata skor kepercayaan diri anak pada pra tindakan sebesar 22, mengalami peningkatan pada siklus pertama menjadi 28 dan siklus kedua menjadi 41.

Kata Kunci: Anak Usia Dini, Kepercayaan diri, Metode talking stick 


\section{PENDAHULUAN}

Kondisi dan stimulasi yang
sesuai dengan kebutuhan anak
sangat dibutuhkan $\begin{array}{r}\text { untuk } \\ \text { mengembangkan }\end{array}$
$\begin{aligned} & \text { kemampuan anak serbainga } \\ & \text { perkembangan anak akan lebih }\end{aligned}$
optimal. Pendidikan Anak Usia Dini
(PAUD). Salah satu bentuk satuan
PAUD yang terdapat pada jalur pendidikan formal adalah Taman Kanak-kanak (TK). Kepercayaan diri perlu dimunculkan dan dilatih pada anak usia dini agar anak memiliki keyakinan bahwa anak mampu mengerjakan segala sesuatu dan mengatasi hambatan untuk mencapai suatu tujuan yang diinginkan.

Berdasarkan pengamatan yang dilakukan peneliti pada TK ABA 01 yang berjumlah 14 anak. Dua belas dari 14 anak kelompok B masih belum berkembang kepercayaan dirinya. Ditunjukkan pada perilaku (1) malu dan ragu akan kemampuan yang dimiliki; (2) kurang dapat berinteraksi dengan baik; (3) memiliki tanggung jawab yang masih rendah; dan (4) tidak suka dengan tantangan.

Salah satu solusi yang dapat membangun kepercayaan diri anak adalah pelaksanaan metode talking stick. Metode talking stick merupakan salah satu metode yang mampu mengembangkan keberanian anak untuk tampil mengungkapkan pengetahuan yang dimiliki dan memberikan kesempatan kepada anak untuk menjalin hubungan interaksi. Melalui metode talking stick anak akan berusaha memotivasi dirinya untuk bisa mengerjakan segala sesuatu dengan percaya diri. Tujuan metode talking stick adalah untuk meningkatkan kepercayaan diri anak melalui tugas yang harus mereka kerjakan seperti menjawab pertanyaan, bercerita, menempel, bernyanyi dan sebagainya.

Berdasarkan permasalahan kepercayaan diri yang dialami anak kelompok B TK ABA 01 Kabupaten Malang sebagaimana yang dipaparkan, dapat digunakan sebagai alternatif pemecahan masalah dalam kepercayaan diri anak yaitu dengan pelaksanaan metode talking stick.

\section{KAJIAN TEORITIK}

\section{Kepercayaan Diri}

Percaya diri berarti merasa positif tentang apa yang bisa dilakukan dan tidak mengkhawatirkan apa yang tidak bisa dilakukan, akan tetapi memiliki kemauan untuk belajar (Perry, 2005). Sejalan dengan Perry, Fatimah menyatakan bahwa kepercayaan diri adalah sikap positif seorang individu dalam mengembangkan penilaian positif, baik terhadap diri sendiri maupun orang lain atau situasi lain yang dihadapinya (Fatimah, 2006). Kepercayaan diri merupakan salah 
satu aspek penting dalam mengembangkan segala potensi, seperti pendapat Adler yang mengatakan bahwa kebutuhan manusia yang paling penting adalah kebutuhan akan kepercayaan pada diri sendiri dan rasa superioritas (Sujianto, Agus., Lubis, Halem., Hadi, 2008). Pada masa mendatang, diharapkan anak usia dini menjadi pribadi yang sukses dengan bekal kepercayaan diri yang tinggi. Kepercayaan diri perlu dilatih dan dikembangkan sejak usia sedini mungkin, khususnya pada masa golden age dimana kemampuan otak anak dapat berkembang hingga $80 \%$. Dari beberapa pengertian di atas dapat disimpulkan bahwa kepercayaan diri adalah kecenderungan untuk (1) menilai positif pada diri sendiri (2) memiliki keyakinan dalam melaksanakan tugas, dan (3) keberanian mengatasi hambatan.

Anak dengan kempuan percaya diri akan memberikan banyak keuntungan untuk diri sendiri. Yoder $\&$ Proctor menyebutkan anak yang percaya diri memiliki kemampuan untuk (1) bersikap tegas, (2) teguh pada keyakinannya, bahkan ketika orang lain melawannya, (3) mudah bergaul dengan teman yang baru, (4) menyelesaikan pekerjaan sampai ia telah merasa menjadi yang terbaik, (5) mengatasi kekalahan dan penolakan dengan tenang namun akan cepat bangkit kembali dengan penuh semangat, (6) dapat bekerja sama dengan orang lain, dan (7) berani memimpin dengan tepat dan tanpa ragu (Yoder, Jean \& Proctor, 1988).

Terdapat beberapa karya ilmiah yang tertuang dalam bentuk tesis, jurnal yang relevan dan menyatakan bahwa kepercayaan diri anak usia dini akan meningkat jika diberikan stimulasi yang tepat. Masropah merancang kegiatan outbond yang hasilnya menunjukkan banyak manfaat dalam pembelajaran dan salah satunya untuk meningkatkan kepercayaan diri anak (Masropah, 2011). Selain itu, Dyson dalam penelitiannya yang bertujuan untuk membiasakan sikap percaya diri pada anak berhasil menemukan bahwa peningkatan peran orang tua, sekolah, dan masyarakat untuk bersama memberi kesempatan pada anak untuk mengembangkan kepercayaan diri mereka (Dyson, 2012). Orang tua dan guru memberikan motivasi serta pujian agar anak semakin memiliki kepercayaan diri (Goleniowska, 2014).

\section{Metode talking stick}

Metode talking stick bukanlah metode yang baru diterapkan khususnya di Indonesia. Metode talking stick sebelumnya telah banyak digunakan dalam pembelajaran pada berbagai mata pelajaran. Talking stick bertujuan untuk mengetahui kesiapan dan penguasaan materi yang dimiliki 
siswa. Locust menyatakan bahwa talking stick telah digunakan oleh banyak suku Indian selama berabadabad sebagai sarana keadilan dan untuk mendengarkan pendapat secara seimbang (Fujioka, 2012). Tongkat berbicara biasa digunakan pada kalangan dewan untuk memutuskan siapa yang berhak untuk berbicara. Ketika seseorang ingin menyampaikan pembicaraan, mereka akan memegang tongkat berbicara, dan tongkat akan bergulir dari satu orang ke orang yang lain sampai semua yang ingin berbicara telah melakukannya.

Tongkat berbicara juga dapat digunakan untuk membantu guru dalam pembelajaran di dalam kelas. Candler menyebutkan bahwa tongkat berbicara adalah strategi yang mendorong semua peserta didik untuk berpartisipasi dalam diskusi (Candler, 2013). Kegiatan ini dilakukan dengan memberikan 2 atau 3 tongkat pada setiap peserta didik untuk digunakan selama diskusi, sebagai penanda peserta didik ingin berbicara. Ketika peserta didik dipanggil, tongkat ditempatkan dalam cangkir atau wadah. Seorang peserta didik hanya dapat merespon sampai peserta didik kehabisan tongkat; peserta didik juga harus mendengarkan tanggapan dari temannya. Selain itu, terdapat kartu diskusi yang dipersiapkan untuk membantu memfasilitasi diskusi dan fokus pada topik tertentu. Strategi ini dapat digunakan dalam setiap mata pelajaran, terutama dalam membaca, ilmu pengetahuan, dan ilmu sosial. Tongkat Berbicara dapat digunakan pada seluruh kelas, pada kelompok kecil, atau di kelompok pembelajaran kooperatif kegiatan membaca dengan duduk melingkar.

Penggunaan metode talking stick cukup mudah. Guru hanya perlu menyiapkan sebuah tongkat untuk kemudian diberikan pada peserta didik dan mereka harus menjawab pertanyaan tentang materi pada hari itu. Langkah-langkah penerapan model pembelajaran tongkat berbicara (talking stick) menurut Suprijono adalah (1) guru menyiapkan sebuah tongkat, (2) guru menyampaikan materi pokok yang akan dipelajari, kemudian memberikan kesempatan kepada peserta didik untuk membaca dan mempelajari materi yang ada pada buku, (3) setelah itu peserta didik diminta untuk menutup buku, (4) guru mengambil tongkat dan memberikan kepada peserta didik, (5) guru memberikan pertanyaan pada peserta didik yang memegang tongkat, dan peserta didik tersebut harus menjawabnya (Suprijono, 2011). Demikian seterusnya sampai semua peserta didik mendapat bagian untuk menjawab setiap pertanyaan dari guru, dan (6) guru memberikan simpulan.

Berdasarkan pengamatan dan penelaahan berkaitan dengan judul, terdapat beberapa karya ilmiah yang tertuang dalam bentuk tesis, jurnal 
yang relevan dan menyatakan bahwa dengan metode talking stick dapat meningkatkan kepercayaan diri anak usia dini. Fujioka (2012) dalam penelitiannya yang bertujuan untuk mengatasi perbedaan dalam kelas multikultural mendapatkan hasil bahwa dengan menggunakan metode talking stick, peserta didik merasa lebih berani mengungkapkan pengetahuannya kepada teman satu kelas.

\section{METODOLOGI PENELITIAN}

Metode yang digunakan adalah penelitian tindakan (action research). Penelitian tindakan adalah penelitian yang berorientasi pada penerapan tindakan dengan tujuan pemecahan masalah atau peningkatan mutu pada sekelompok subyek yang diteliti dan mengamati tingkat keberhasilan atau akibat dari tindakannya, untuk kemudian diberikan tindakan selanjutnya yang bersifat menyempurnakan tindakan atau penyesuaian dengan kondisi dan situasi sehingga diperoleh hasil yang lebih baik. Kemudian dilanjutkan dengan kajian tindakan melalui beberapa siklus. Sumber data dalam penelitian ini adalah anak kelompok B TK ABA 01 Kabupaten Malang yang berjumlah 14 anak.

Tujuan penelitian ini adalah untuk meningkatkan kepercayaan diri anak usia 5-6 tahun melalui metode talking stick di TK ABA 01 Malang. Desain penelitian yang digunakan adalah model satu siklus atau putaran kegiatan yang meliputi beberapa tahap dari Kemmis dan Taggart. Tahap-tahap pada siklus tersebut meliputi (1) Plan (perencanaan), (2) Action (tindakan) dan Observe (pengamatan), (3) Reflect (refleksi), dan akan dilakukan revisi perencanaan pada siklus selanjutnya jika masih diperlukan.

Kemudian merancang kisi-kisi, sebagai acuan dalam membuat instrumen. Kisi-kisi diambil dari definisi konseptual dan definisi operasional tentang kepercayaan diri anak usia 5-6 tahun sebagai berikut:

Tabel 1. Kisi-kisi Kepercayaan Diri Anak Kelompok B

\begin{tabular}{|c|c|c|}
\hline Aspek & Indikator & Butir \\
\hline \multirow{4}{*}{$\begin{array}{lr}\text { Menilai positif } \\
\text { pada diri } \\
\text { sendiri }\end{array}$} & \multirow{2}{*}{$\begin{array}{l}\text { Mempercayai } \\
\text { kemampuan diri } \\
\text { sendiri }\end{array}$} & $\begin{array}{l}\text { Berani tampil ke depan } \\
\text { kelas }\end{array}$ \\
\hline & & $\begin{array}{l}\text { Menjawab pertanyaan } \\
\text { dengan lancar }\end{array}$ \\
\hline & \multirow[t]{2}{*}{$\begin{array}{l}\text { Mudah bergaul } \\
\text { dengan orang lain }\end{array}$} & $\begin{array}{l}\text { Melakukan percakapan } \\
\text { dengan orang lain }\end{array}$ \\
\hline & & $\begin{array}{l}\text { Berani mengemukakan } \\
\text { pendapat }\end{array}$ \\
\hline \multirow{4}{*}{$\begin{array}{l}\text { Mampu } \\
\text { menyelesaikan } \\
\text { tugas }\end{array}$} & \multirow{2}{*}{$\begin{array}{l}\text { Menyelesaikan } \\
\text { tugas secara } \\
\text { mandiri }\end{array}$} & $\begin{array}{l}\text { Menyelesaikan tugas tanpa } \\
\text { bantuan }\end{array}$ \\
\hline & & $\begin{array}{l}\text { Mengerjakan tugas sampai } \\
\text { selesai }\end{array}$ \\
\hline & \multirow[t]{2}{*}{$\begin{array}{l}\text { Mudah menerima } \\
\text { tanggungjawab }\end{array}$} & $\begin{array}{l}\text { Melaksanakan perintah } \\
\text { dengan baik }\end{array}$ \\
\hline & & Bermain sesuai aturan \\
\hline \multirow[t]{4}{*}{$\begin{array}{l}\text { Mengatasi } \\
\text { kesulitan }\end{array}$} & \multirow[t]{2}{*}{$\begin{array}{l}\text { Siap menghadapi } \\
\text { tantangan }\end{array}$} & $\begin{array}{l}\text { Berani menunjukkan hasil } \\
\text { karya }\end{array}$ \\
\hline & & Berani memimpin \\
\hline & \multirow{2}{*}{$\begin{array}{l}\text { Menghadapi } \\
\text { kegagalan dengan } \\
\text { tenang }\end{array}$} & $\begin{array}{l}\text { Menunjukkan sikap tidak } \\
\text { mudah putus asa }\end{array}$ \\
\hline & & $\begin{array}{l}\text { Melakukan kegiatan } \\
\text { dengan semangat }\end{array}$ \\
\hline
\end{tabular}


Berdasarkan pendapat yang diungkapkan oleh Mills bahwa keberhasilan tindakan yang dimaksud dalam penelitian ini adalah apabila minimal $71 \%$ dari anak yaitu 10 dari 14 anak mencapai tingkat capaian perkembangan minimal (Mills, 2000). Tingkat capaian perkembangan (TCP) minimal yang ditentukan peneliti dan kolaborator yaitu sebesar $75 \%$ dari TCP maksimal.

TCP Maksimal $=\sum$ Butir $\mathrm{x}$ kategori

$$
\begin{aligned}
& =12 \times 4 \\
& =48
\end{aligned}
$$

$$
\begin{aligned}
\text { TCP Minimal } & =\frac{75}{100} \times 48 \\
& =36
\end{aligned}
$$

Jika dikonversikan ke nilai $=\frac{36}{48} \times 100=75$

\section{HASIL DAN PEMBAHASAN}

Penelitian dilakukan di TK ABA 01 Malang tepatnya di kelompok B dengan jumlah 14 anak. Peneliti juga melakukan kolaborasi dengan guru untuk melakukan penilaian kepercayaan diri pada pra tindakan untuk mengetahui kondisi awal kepercayaan diri.

\section{Deskripsi Data Pratindakan}

Sebelum melakukan penelitian, data awal tentang proses pembelajaran dan data awal kepercayaan diri anak yang akan diteliti dikumpulkan terlebih dahulu. Rata-rata tingkat capaian perkembangan (TCP) yang diperoleh anak kelompok B TK ABA 01 adalah sebesar 22 dan berada pada kategori mulai berkembang (MB). Hasil penilaian pra tindakan menunjukkan bahwa nilai anak berada jauh di bawah target. Target yang disepakati bersama kolaborator adalah $75 \%$ dari TCP maksimal, artinya TCP minimal anak adalah 36 dari 48. Berdasarkan data asesmen awal, tindakan yang disepakati bersama kolabolator adalah penerapan metode talking stick untuk meningkatkan kepercayaan diri anak.

\section{Tindakan Siklus I}

Tahap-tahap pada penelitian tindakan ini adalah tahap perencanaan, tindakan, pengamatan, dan refleksi. Perencanaan intervensi tindakan mencakup (1) membuat rencana kegiatan harian (RKH) selama dua belas kali pertemuan, (2) menyiapkan media pembelajaran untuk dua belas kali pertemuan, (3) menyiapkan alat pengumpul data berupa catatan observasi, catatan wawancara, lembar observasi dan catatan dokumentasi.

Tindakan dan pengematan pada siklus I dilakukan sebanyak empat kali dalam seminggu sampai mencapai dua belas kali pertemuan. Alokasi waktu dalam pelaksanaan metode talking stick adalah 60 menit setiap kali pertemuan. Berikut hasil peningkatan saat pratindakan dan siklus I: 
Tabel 2. Kepercayaan Diri Anak Kelompok B pada Pratindakan dan Siklus I

\begin{tabular}{|c|c|c|c|c|c|}
\hline \multirow{3}{*}{ No } & \multirow{3}{*}{$\begin{array}{l}\text { Nama } \\
\text { Anak }\end{array}$} & \multicolumn{2}{|c|}{$\begin{array}{c}\text { Pra } \\
\text { Tindakan }\end{array}$} & \multicolumn{2}{|c|}{ Siklus I } \\
\hline & & TCP & Kate & TCP & Kate \\
\hline & & Anak & gori & Anak & gori \\
\hline 1 & ALK & 17 & $\mathrm{BB}$ & 24 & MB \\
\hline 2 & CAP & 27 & MB & 36 & $\mathrm{BSH}$ \\
\hline 3 & EGK & 22 & MB & 27 & MB \\
\hline 4 & KAS & 23 & MB & 28 & $\mathrm{MB}$ \\
\hline 5 & KPA & 26 & MB & 33 & BSH \\
\hline 6 & LTZ & 29 & MB & 37 & BSH \\
\hline 7 & MHB & 22 & MB & 26 & MB \\
\hline 8 & MKD & 25 & MB & 28 & MB \\
\hline 9 & MNM & 18 & $\mathrm{BB}$ & 20 & BB \\
\hline 10 & MRK & 24 & MB & 31 & $\mathrm{BSH}$ \\
\hline 11 & NTM & 24 & MB & 33 & BSH \\
\hline 12 & OIK & 25 & MB & 34 & BSH \\
\hline 13 & RAP & 16 & BB & 19 & BB \\
\hline 14 & ZAP & 17 & BB & 19 & BB \\
\hline \multicolumn{2}{|c|}{ Jumlah } & 311 & MB & 394 & MB \\
\hline
\end{tabular}

Dari tabel di atas dapat dilihat bahwa kepercayaan diri anak mengalami peningkatan setelah diberi tindakan berupa metode talking stick. Pada siklus I, 14 anak diberi tindakan, terdapat dua anak yang meraih TCP tertinggi dan masuk kategori berkembang sesuai harapan $(\mathrm{BSH})$ yaitu $\mathrm{CAP}$ dengan perolehan TCP sebesar 36 dan LTZ dengan perolehan TCP sebesar 37. Empat anak lainnya mengalami peningkatan dan masuk dalam kategori berkembang sesuai harapan (BSH) dengan interval TCP antara 31-33. Lima anak mengalami peningkatan dan berada pada kategori mulai berkembang (MB) dengan interval TCP antara 24-28, sedangkan tiga anak sisanya berada pada kategori belum berkembang (BB) dengan perolehan TCP sebesar 20 yaitu MNM dan TCP sebesar 19 yaitu RAP dan ZAP.

Rata-rata TCP anak pada pra tindakan sebesar 22 mengalami peningkatan menjadi 28 pada siklus I. Berdasarkan kategori yang ditentukan sebelumnya, rata-rata TCP anak pada siklus I termasuk dalam kategori mulai berkembang (MB). Setelah melakukan tindakan dalam dua belas kali pertemuan, peneliti dan kolaborator melakukan refleksi untuk perbaikan pada siklus II.

Hasil refleksi yang telah didiskusikan oleh peneliti bersama kolaborator adalah (1) guru masih kurang dalam memotivasi anak untuk tampil ke depan kelas, (2) anak tampak bosan dengan metode pemberian tongkat, (3) masih ada beberapa anak yang malu untuk tampil di depan kelas, (4) guru menyiapkan kain untuk menutup mata yang digunakan saat pemberian tongkat, (5) guru menunjuk anak dengan cara menggulirkan tongkat, (6) pada siklus I hanya ada dua anak yang sudah mencapai TCP minimal, hal tersebut berarti bahwa penelitian belum mencapai target yang ditentukan, sehingga penelitian akan dilanjutkan pada siklus II. 


\section{Tindakan Siklus II}

Tindakan pada siklus II adalah peningkatan kepercayaan diri anak melalui metode talking stick dengan beberapa perbaikan berdasarkan refleksi siklus I. Tahap-tahap pada penelitian tindakan ini adalah tahap perencanaan, tindakan dan pengamatan, dan refleksi. Perencanaan tindakan sama dengan siklus I namun dilakukan perbaikan pada proses tindakan siklus II diantaranya adalah mengkondisikan anak untuk melakukan kompetisi, memberi motivasi lebih pada anak yang masih kurang kepercayaan dirinya, merangsang anak untuk berani mengemukakan pendapat dan berkomunikasi dengan lancar, memberi motivasi agar anak berani menjadi pemimpin dan tampil di depan kelas untuk melaksanakan perintah guru.

Pada perencaan siklus II, dilakukan perbaikan pembelajaran sesuai hasil refleksi pada siklus I. Perbaikan yang direncanakan ialah diadakannya perlombaan pada siklus II dan memberi motivasi pada anak agar lebih percaya diri. Proses kegiatan pembelajaran selama dua belas kali pertemuan. Berikut hasil peningkatan saat pra tindakan, siklus I, dan siklus II:
Tabel 3. Kepercayaan Diri Anak

Kelompok B pada Pratindakan, Siklus I dan Siklus II

\begin{tabular}{|c|c|c|c|c|c|c|c|}
\hline \multirow{3}{*}{ No } & \multirow{3}{*}{$\begin{array}{l}\text { Nama } \\
\text { Anak }\end{array}$} & \multicolumn{2}{|c|}{$\begin{array}{l}\text { Pra } \\
\text { ndakan }\end{array}$} & \multicolumn{2}{|c|}{ Siklus I } & \multicolumn{2}{|c|}{ Siklus II } \\
\hline & & TCP & Kate & TCP & & TCP & $\mathrm{Ka}$ \\
\hline & & Anak & gori & Anak & gori & Anak & gori \\
\hline 1 & ALK & 17 & $\mathrm{BB}$ & 24 & MB & 38 & BSH \\
\hline & CAP & 27 & $\mathrm{MB}$ & & $\mathrm{sH}$ & & BSE \\
\hline 3 & EGK & 22 & $\mathrm{MB}$ & 27 & $\mathrm{MB}$ & 42 & BSB \\
\hline 7 & KAS & 23 & $\mathrm{MB}$ & 28 & MB & 45 & $\overline{\mathrm{BSB}}$ \\
\hline 5 & $\mathrm{KPA}$ & 26 & $\mathrm{NB}$ & & $\mathrm{HH}$ & & \\
\hline 6 & LTZ & 29 & MB & 37 & BSH & 47 & BSB \\
\hline 7 & MHB & 22 & MB & 26 & $\overline{M B}$ & 40 & $\overline{B S B}$ \\
\hline 8 & MKD & 25 & $\mathrm{MB}$ & 20 & NB & 72 & $\mathrm{BSB}$ \\
\hline 9 & MNM & 18 & $\mathrm{BB}$ & 20 & $\mathrm{BB}$ & 37 & $\overline{\mathrm{BSH}}$ \\
\hline 10 & MRK & 24 & MB & 31 & BSH & 42 & BSB \\
\hline 11 & NTM & 24 & MB & 33 & BSH & 45 & BSB \\
\hline 12 & OIK & 25 & $\mathrm{MB}$ & 34 & $\mathrm{BSH}$ & 46 & BSB \\
\hline 13 & RAP & 16 & $\mathrm{BB}$ & 19 & BB & 31 & $\mathrm{BSH}$ \\
\hline 17 & ZAP & 17 & BB & 19 & BB & 30 & $\mathrm{BSH}$ \\
\hline & & 311 & & 394 & & 573 & \\
\hline & & 22 & & 28 & & 41 & \\
\hline
\end{tabular}

Berdasarkan data di atas, terdapat dua anak yang belum mencapai target yaitu RAP dengan perolehan TCP sebesar 31 dan ZAP dengan perolehan TCP sebesar 30 . Meski demikian, kepercayaan diri RAP dan ZAP meningkat setelah diberi interversi pada siklus I dan siklus II. Sementara 12 anak yang lain dinyatakan telah mencapai target karena memperoleh TCP diatas TCP minimal yang ditentukan, rentang TCP yang diperoleh anak adalah antara 37-47. TCP tertinggi diraih oleh LTZ yaitu sebesar 47 dari TCP maksimal 48. 
Rata-rata TCP anak pada pra tindakan sebesar 22 dan sebesar 28 pada siklus I mengalami peningkatan menjadi 41 pada siklus II ditentukan sebelumnya, rata-rata TCP anak pada siklus II termasuk dalam kategori berkembang sangat baik (BSB). Seperti kesepakatan pada awal penelitian, target yang ditentukan ialah $71 \%$ dari jumlah anak yakni 10 dari 14 anak mencapai TCP minimal 36 dari TCP maksimal 48.

Berdasarkan data asesmen dari pratindakan sampai siklus II, ratarata TCP anak mencapai lebih dari TCP minimal 36 yakni sebesar 41 dan jumlah anak yang mencapai TCP lebih dari $71 \%$. Hal tersebut membuktikan bahwa dalam penelitian ini dinyatakan berhasil meningkatkan kepercayaan diri anak karena mampu melebihi TCP yang telah ditentukan. Dari hasil penelitian dapat disimpulkan bahwa kepercayaan diri anak kelompok B TK ABA 01 Kabupaten Malang dapat meningkat melalui metode talking stick. Setelah melakukan tindakan dalam dua belas kali pertemuan, peneliti dan kolaborator melakukan refleksi setelah melaksanakan siklus II.

Hasil refleksi yang telah didiskusikan oleh peneliti bersama kolaborator adalah sebagai berikut: (1) guru sudah maksimal dalam memberikan motivasi kepada anak untuk tampil ke depan kelas sehingga anak tampak bersemangat dan berani tampil di depan kelas tanpa dibujuk terlabih dahulu oleh guru, (2) Metode pemberian tongkat lebih bervariasi dan disenangi anak, (3) sebagian besar anak semangat tampil ke depan kelas dan antusias melakukan perlombaan, (4) anak dapat aktif dalam bercakap-cakap dan berinteraksi baik dengan teman, dan (5) selama pelaksanaan siklus II anak sudah menunjukkan peningkatan kepercayaan diri dengan rata-rata TCP 41 dari TCPmax 48. Hal ini membuktikan bahwa pelaksanaan metode talking stick dapat meningkatkan kepercayaan diri anak kelompok B TK ABA 01 Kabupaten Malang.

\section{KESIMPULAN DAN SARAN}

Hasil penelitian menunjukkan bahwa kepercayaan diri anak kelompok B di TK ABA 01 Malang dapat ditingkatkan dengan pelaksanaan metode talking stick. Terbukti dari rata-rata TCP pada pra tindakan adalah sebesar 22, pada siklus I meningkat menjadi 28, dan pada siklus II meningkat mencapai 41.

Saran untuk guru TK adalah diharapkan lebih dapat menstimulasi dan memotivasi anak secara optimal agar anak dapat mengembangkan kepercayaan dirinya. Guru juga perlu untuk terus mengembangkan teknik atau metode yang dapat meningkatkan kepercayaan diri anak. Bagi peneliti selanjutnya diharapkan dapat melakukan kajian 
penelitian baik secara empiris
maupun teoritis tentang
pengembangan kepercayaan diri anak melalui berbagai penggunaan teknik atau metode pembelajaran yang sesuai dengan perkembangan anak.

\section{DAFTAR PUSTAKA}

Candler, L. (2013). Talking Sticks Discussions. Teaching Resources. London: Routledge.

Dyson, L. (2012). Strategies for and Successes with Promoting Social Integration in Primary Schools in Canada and China.

Fatimah, E. (2006). Psikologi Perkembangan Peserta Didik.

Fujioka, K. D. (2012). The talking stick: an American Indian Tradition in the ESL Classroom.

Goleniowska, H. (2014). The importance of developing confidence and selfesteem in children with a learning disability. Journal of Advances in Mental Health and Intellectual Disabilities.

Masropah. (2011). Meningkatkan Kepercayaan Diri Anak Usia Dini melalui Kegiatan Outbound.

Mills, G. E. (2000). Action Research: a guide for teacher researcher.

Perry, M. (2005). Confidence Boosters Pendongkrak Kepercayaan Diri.

Sujianto, Agus., Lubis, Halem., Hadi, T. (2008). Psikologi Kepribadian.

Suprijono, A. (2011). Cooperative Learning Teori dan Aplikasi Paikem.
Yoder, Jean \& Proctor, W. (1988). The Self-Confident Child. 